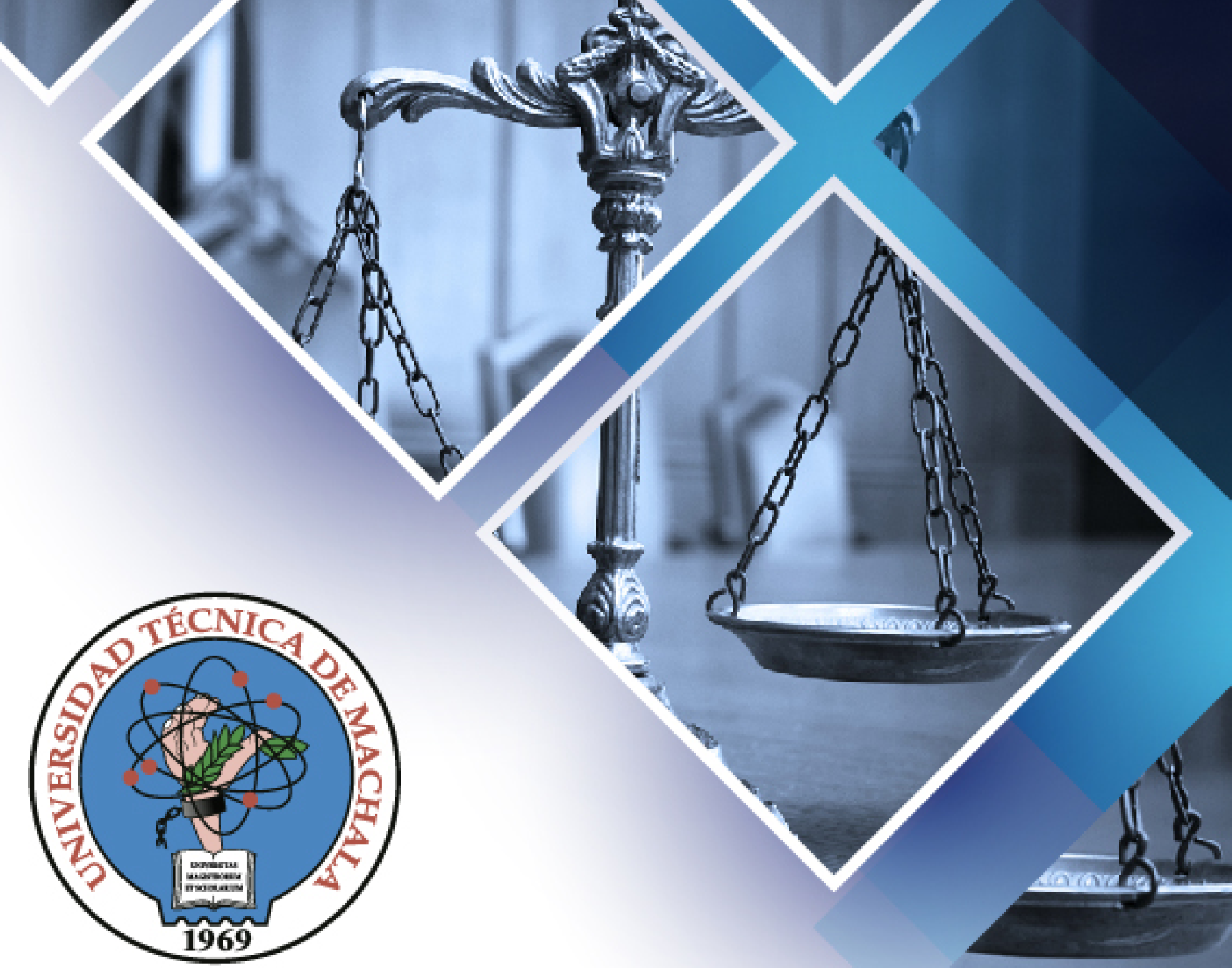

Constitucionales Edición 2021

José Eduardo Correa Calderón Compilador

coloción: Semana de la ciencia $\triangleq \mathrm{y}_{\mathrm{A}} \mathrm{d}_{\mathrm{UTMACH}}^{\mathrm{i}}$ 


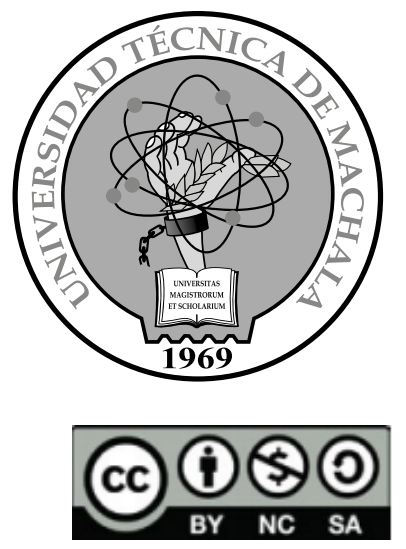

Ediciones UTMACH 156 pág: $21 \times 25,5 \mathrm{~cm}$

Colección Semana de la Ciencia

Título: Balances Constitucionales - Edición 2021 José Eduardo Correa Calderón (Compilador)

Primera edición - julio 2021

ISBN: 978-9942-24-146-7

CDD 340.56

Publicación PDF 


\section{Balances Constitucionales Edición 2021}


José Eduardo Correa Calderón COMPILADOR 
César Quezada Abad - Rector

Amarilis Borja Herrera - Vicerrector Académico

Jhonny Pérez Rodríguez - Vicerrector Administrativo

Luis Brito Gaona

Director de Investigación

( ) Ediciones UTMACH

Colección Semana de la Ciencia

Título original:

Balances Constitucionales

Edición 2021

ISBN: 978-9942-24-146-7

DOI: http://doi.org/10.48190/9789942241467

Libro con revisión de pares ciegos especializados

๑ José Eduardo Correa Calderón (Compilador)

(c) Autores de capítulos

Karina Lozano Zambrano Jefe editor / Diseño y edición editorial Edison Mera León - Diseño de portada

Fernanda Tusa Jumbo - Corrector de estilos Jorge Maza-Cordova - Asesor tecnológico

Karla Ibañez y Cyndi Aguilar - Equipo de difusión

Primera edición Julio 2021

Machala-Ecuador

Universidad Técnica de Machala - UTMACH

Correo: editorial@utmachala.edu.ec

Licencia Creative Commons Atribución-NoComercial-CompartirIgual 4.0 Internacional

(CC BY-NC-SA 4.0). 


\section{Contenido}

La reparación integral como derecho y principio: estudio aplicado a las sentencias constitucionales de Machala, Ecuador

El principio de exigibilidad de los derechos constitucionales, experiencias desde la Corte Constitucional del Ecuador

La prueba en garantias jurisdiccionales:

Poderes Probatorios, Derecho de Defensa, y Libertad Probatoria

Los Derechos del Buen Vivir, la polémica entre el contenido esencial y exigibilidad

El Estado de Excepción en Ecuador: deformación y abuso del poder a partir de la Constitución de Montecristi

Los gobiernos regionales en el Ecuador: análisis de las causas que han devenido en una utopía constitucional
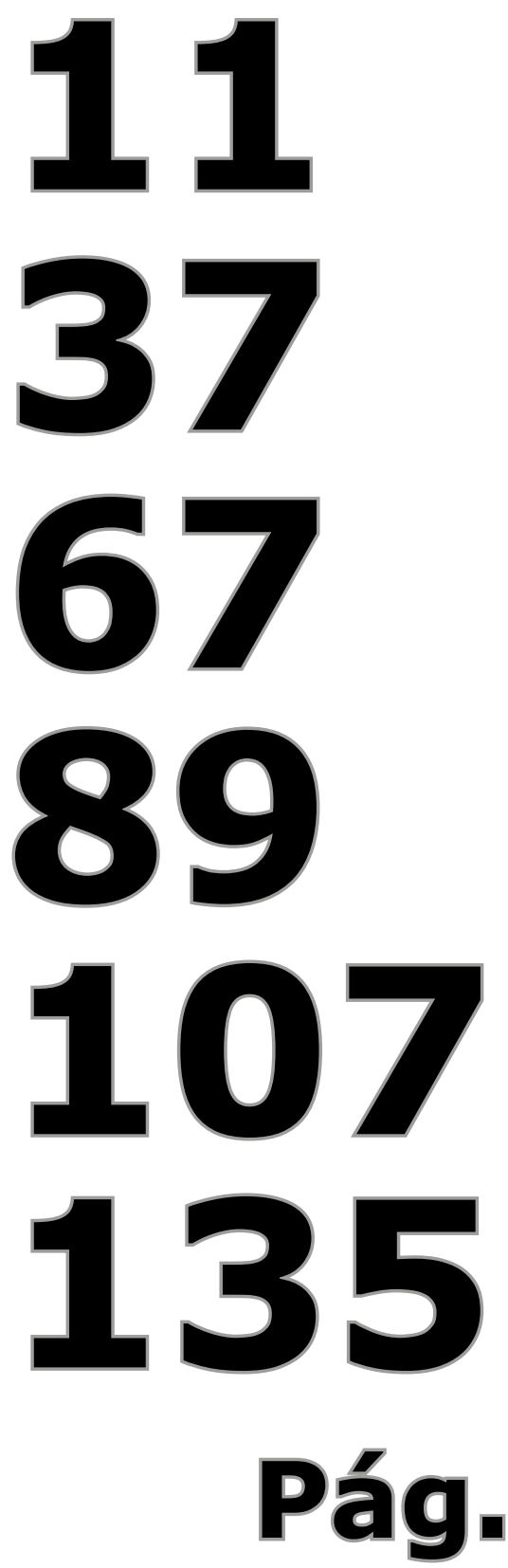


\section{Introducción}

La Constitución de Montecristi ha superado la barrera de la primera década, suerte con la que no corrió la Constitución del 98 y muchas otras que han pasado por la vida republicana del Ecuador. Una Norma Constitucional que, como podemos recordar, se construyó fuertemente incluenciada por las demandas de los movimientos sociales, necesita de una veeduría permanente por la sociedad y, por supuesto, por la academia. El ambicioso texto constitucional que fue aprobado por una abrumadora mayoría mediante referendum, inclinó su balanza hacia el respeto a los derechos y abría paso al Estado Constitucional de Derechos y Justicia, permitiendo que la Constitución se convierta, como nunca antes, en norma viva para el ejercicio del derecho interno.

El amplio catálogo de derechos y el sistema de justicia constitucional que se inauguró en 2008, ha ido encontrando su camino a lo largo de estos primeros años, con muchos aciertos y tropiezos, pero sobre todo con la certeza de que llegó para quedarse. En ese sentido, el nacimiento de la Corte Constitucional y sus sentencias han jugado un papel fundamental, en función de lo cual, hoy por hoy, son de estudio obligatorio en las aulas universitarias y en el ejercicio profesional. Sin duda, la jurisprudencia constitucional es una importante herramienta del Estado en este proceso de refundación.

En virtud de lo expuesto, desde la Universidad Técnica de Machala esperamos aportar en ese indispensable ejercicio ciudadano de analizar de forma permanente el cumplimiento del proyecto constitucional, y ponemos en vuestra consideración la presente obra titulada "Balances Constitucionales", que recoge varios trabajos 
impulsados desde la Dirección de Investigación, la Carrera de Derecho y la Maestría en Derecho y Justicia Constitucional, en el marco de la Colección Semana de la Ciencia.

Así, el primer trabajo se titula "La reparación integral como derecho y principio: estudio aplicado a las sentencias constitucionales de Machala, Ecuador”, el cual es presentado por los profesores José Correa, Gabriel Orellana, Anibal Campoverde y Ruth Mosoco, y forma parte de los resultados del Proyecto de Investigación denominado "La reparación integral a las violaciones de derechos en las sentencias de garantías jurisdiccionales de los juzgados y tribunales de Machala” en los años 2016 y 2017, que se llevó a cabo por parte del Grupo de Investigación en Derecho de la Universidad Técnica de Machala. El trabajo parte de la premisa de que no se podría alcanzar justicia sin que exista una reparación integral como consecuencia de la vulneración de derechos constitucionales que atenten contra la dignidad de las personas, repasa las lineas jurisprudenciales de la Corte Constitucional sobre reparación integral y evalúa su aplicación por parte de las juezas y jueces del cantón Machala, en la provincia de El Oro.

El segundo trabajo se titula "El principio de exigibilidad de los derechos constitucionales, experiencia desde la Corte Constitucional del Ecuador”, presentado por la Dra. Wendy Molina Andrade que, desde su experiencia como Jueza de la Corte Constitucional, con mucho acierto aborda las características del principio de exigibilidad a través de un nuevo paradigma constitucional que deja clara como finalidad material del Estado garantizar los derechos de las personas de una manera efectiva, reforzando el rol del Juez frente al resto de las funciones del Estado a fin de hacer de la Constitución una norma de aplicación directa en todas las esferas jurídicas.

El tercer trabajo se titula "La prueba en garantías jurisdiccionales: poderes probatorios, derecho a la defensa y libertad probatoria”, presentado por Diego Idrovo, catedrático de la Universidad de Cuenca y Profesor Invitado en la Maestría en Derecho y Justicia Constitucional, acompañado de María Caridad Rojas. En este trabajo podremos observar una dura crítica a la ausencia normativa sobre la actuación y práctica de la prueba en los procesos de garantías jurisdiccionales, resaltando la necesidad de contar con una efectiva regulación en este tema de trascendental importancia, cuyas reglas difieren abiertamente de las establecidas en el Código Orgánico General de Procesos.

El cuarto trabajo que ponemos en vuestra consideración se titula "Los derechos del buen vivir: la polémica entre contenido y exigibilidad”, el cual es presentado por Juan Cando Pacheco, profesor fundador de la Carrera de Derecho de la UTMACH. 
En este trabajo analiza las diferentes corrientes de pensamiento que cuestionan la exigibilidad a los derechos sociales, así como las tenciones políticas sobre el origen y el contenido de los derechos sociales, entre los defensores de la tesis de que los derechos sociales son enunciados programáticos y aquellos que defienden la tesis de que los referidos derechos tienen la misma trascendencia que los derechos civiles y políticos.

Los dos trabajos finales tienen un valor especial, ya que recogen la participación de nuestros recién graduados y sus aportes producto de las investigaciones realizadas en sus procesos de titulación, cuyos trabajos finales fueron dirigidos por el profesor José Correa.

Así, el quinto trabajo de la presente obra realiza un balance sobre las atribuciones extraordinarias del Presidente de la República y se titula "El estado de excepción en ecuador: deformación y abuso de poder a partir de la constitución de Montecristi”, bajo la autoría de Thalía Veintimilla y Belén Aguilera. En este capítulo, se realizan tres críticas necesarias: la primera respecto a la errada función preventiva que se le ha venido dando al Estado de Excepción; la segunda, enunciada como una deformación de la limitación del principio de territorialidad y temporalidad, donde se puede verificar más de un exceso por parte del Ejecutivo; y, la tercera crítica sobre el uso de las medidas extraordinarias como herramineta para el abuso de poder.

El sexto y último capítulo de esta obra, se titula "Los gobiernos regionales en el Ecuador: análisis de las causas que han devenido en una utopía constitucional” y sus autores son Alejandra Herrera y Ariel Córdova. La investigación trata de poner en evidencia las causas que han hecho imposible la consolidación de los Gobiernos Regionales que, sin duda, era una apuesta política del proyecto constitucional de Montecristi. Más de una década después, no se ha logrado conformar ningún Gobierno Regional y existe la sensación de que, al menos en un futuro cercano, pueda conformarse alguno. En ese sentido, la aspiración constituyente no pasa de ser una utopía que simplemente adorna la Constitución.

De esta forma, esperamos que los trabajos que presentamos sirvan para el debate académico y social, y que motiven la generación y publicación de nuevas investigaciones que analicen y evalúen el cumplimiento de nuestra Carta Constitucional. 

La reparación integral como derecho y principio: Estudio aplicado a las sentencias constitucionales de Machala, Ecuador

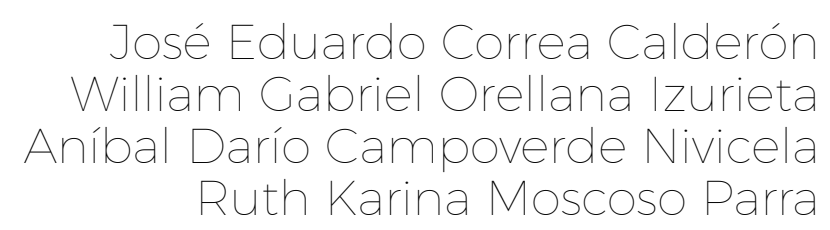




\section{AUTORES}

José Eduardo Correa Calderón

Universidad Técnica de Machala

jecorrea@utmachala.edu.ec

William Gabriel Orellana Izurieta

Universidad Técnica de Machala

worellana@utmachala.edu.ec

Aníbal Darío Campoverde Nivicela

Universidad Técnica de Machala

acampoverde@utmachala.edu.ec

\section{Ruth Karina Moscoso Parra}

Universidad Técnica de Machala

rmoscoso@utmachala.edu.ec 


\section{La reparación integral como derecho y principio: Estudio aplicado a las sentencias constitucionales de Machala, Ecuador}

\section{Contenido}

Introducción. 1. La reparación integral como Derecho. 2. La reparación integral como Principio. 3. Aplicación de los precedentes de la Corte Constitucional en la justicia constitucional ordinaria: casos relevantes de las Unidades Judiciales con sede en el Cantón Machala y Salas de la Corte Provincial de El Oro, en los años 2016 y 2017. Conclusiones

Palabras clave: Reparación integral, Justicia, Derechos humanos. 


\section{Introducción}

El presente trabajo se propone como parte de los resultados del Proyecto de Investigación denominado "La reparación integral a las violaciones de derechos en las sentencias de garantías jurisdiccionales de los juzgados y tribunales de Machala” en los años 2016 y 2017, que se llevó a cabo por profesores del Grupo de Investigación en Derecho de la Universidad Técnica de Machala; donde partimos de la idea de que no se podría alcanzar la justicia sin que exista una reparación integral como consecuencia de la vulneración de derechos constitucionales que atenten contra la dignidad de las personas.

En ese contexto, con la aprobación de la Constitución 2008, en el Ecuador toma fuerza la discusión sobre los asuntos de justicia constitucional, además que, en este nuevo escenario, aparece la Corte Constitucional como un órgano declarado como el de mayor rango en temas de control, interpretación y administración de justicia en esta materia. Entonces, los criterios de esta Corte, que tiene la facultad de emitir sentencias con carácter vinculante, resultan fundamentales al momento de definir el alcance de los preceptos constitucionales, de modo que el Estado Constitucional se complementa con el desarrollo de su jurisprudencia.

De esta forma, como parte de nuestra investigación, consideramos necesario que, previo al análisis de las sentencias en el escenario cantonal local y provincial, se atienda lo dicho por la Corte Constitucional a través de sus sentencias y resoluciones, con el objetivo principal de establecer la noción de reparación integral según su jurisprudencia. Al respecto, conocemos que el Art. 18 de la Ley Orgánica de Garantías Jurisdiccionales y Control Constitucional establece que "en caso de declararse la vulneración de derechos se ordenará la reparación integral por el daño material e inmaterial", concordante con lo establecido la Convención Americana de Derechos Humanos y el Pacto Internacional de Derechos Civiles y Políticos, donde se establece que al Estado le corresponde adoptar las medidas pertinentes para asegurar la reparación integral derivada de vías de hecho que vulneran dichos derechos, como reza en los considerandos del mismo cuerpo de leyes citado.

Coincidiendo con la idea de que "el deber de reparar es uno de los principios del derecho de gentes y se proyecta en dos dimensiones, una internacional y otra interna" (Cárdenas \& Suárez, 2014, pág. 36). La Corte Interamericana de Derechos Humanos, organismo referente en nuestro sistema jurisprudencial de dere-

La reparación integral como derecho y principio: Estudio aplicado a las sentencias constitucionales de Machala, Ecuador 
chos humanos, en la sentencia de fecha 28 de noviembre del 2005 dentro del Caso Blanco Romero y otros vs Venezuela, así como en la sentencia de 07 de febrero de 2006 en el Caso Acevedo Jaramillo y otros vs Perú, se ha pronunciado indicando que "las reparaciones son medidas que tienden a hacer desaparecer los efectos de las violaciones cometidas. Su naturaleza y su monto dependen de las características de la violación y del daño ocasionado en los planos material e inmaterial” (Parr. 70), pues tenemos claro que "los derechos de las víctimas gozan de una concepción amplia, es decir que sus pretensiones no solo se agotan en la reparación económica, pues tienen derecho a ser tratadas con dignidad... y obtener la reparación integral de sus derechos”. (Cepeda \& Ramírez, 2016, pág. 1063)

En este contexto, valiéndonos del análisis de las sentencias de la Corte Constitucional del Ecuador donde se ha desarrollado el concepto de reparación integral, expondremos ante la comunidad científico-jurídica nuestra percepción de la conceptualización que la Corte tiene sobre el tema, que en lo posterior nos servirá para contrastarlo con la actividad de las juezas y jueces constitucionales de primero y segundo nivel y que, a la par, esperamos sirva para su utilización en el litigio constitucional cotidiano.

La Corte Constitucional del Ecuador parte de las directrices que emanan desde los mandatos constitucionales. El numeral 3 del Art. 86 del Texto Constitucional determina que, como resultado de una acción de garantías jurisdiccionales, la jueza o juez resolverá la causa mediante sentencia, y en caso de constatarse la vulneración de derechos, deberá declararla, ordenar la reparación integral, material e inmaterial, y especificar e individualizar las obligaciones, positivas y negativas, a cargo del destinatario de la decisión judicial, y las circunstancias en que deban cumplirse.

Dicho lo cual, de plano queda claro el reconocimiento que el constituyente hizo a la Reparación Integral y que logró plasmar en la Constitución del Ecuador.

A partir de aquello, siendo la Corte Constitucional el máximo órgano de interpretación, control y administración de justicia en materia constitucional, ha desarrollado la concepción de la Reparación Integral, dentro del cual, nuestra investigación identificó una suerte de doble dimensionalidad, considerándola tanto como un derecho que debe garantizarse, cuanto como un principio orientador con alcances ilimitados, según lo describimos a continuación:

La reparación integral como derecho y principio: Estudio aplicado a las sentencias constitucionales de Machala, Ecuador 


\section{La reparación integral como derecho}

Para entender a los derechos subjetivos partimos de la idea tradicional de que son facultades o expectativas de una persona, siempre que sean reconocidas en una norma jurídica o que encuentren su fundamento en la dignidad de la persona humana, en otras palabras, son facultades de los individuos que "el ordenamiento jurídico debe reconocer” (Álvarez, 2001, pág. 28). La violación de un derecho, tiene como consecuencia constitucional inmediata diversos mecanismos para su auxilio que, a su vez, vienen acompañados de más derechos, como la tutela judicial efectiva o la reparación integral a la que hoy hacemos mención.

De alguna forma todos coexisten en el ordenamiento y dependen uno de otro, con igual jerarquía e importancia, con lo cual van quedando de lado aquellas corrientes que pretendían clasificar a los derechos por generaciones, haciéndonos creer que unos podían ser más importantes que otros, que unos eran fundamentales y otros, posiblemente, no.

El Juez Gaviria desde la Corte Constitucional en Colombia nos decía en uno de sus fallos que, "por ejemplo, el derecho a la salud, que no siendo a primera vista fundamental, pasa a gozar de esta categoría cuando se pone en peligro la vida de las personas" ${ }^{\prime}$. Ecuador así lo ha dejado claro en su Constitución cuando introdujo el numeral 6 de su Art. 11 estableciendo que "todos los principios y los derechos son inalienables, irrenunciables, indivisibles, interdependientes y de igual jerarquía”, es decir que, en el derecho constitucional ecuatoriano, no tenemos derechos de primer orden ni segundo o tercero, por el contrario, todos los derechos constitucionalmente reconocidos tienen igual valor, incluso aquellos que no tengan reconocimiento en el texto pero encuentran su fundamento en la dignidad de las personas.

Pues bien, y como ya hemos indicado, para la Corte Constitucional de Ecuador, la reparación integral "se constituye en un verdadero derecho que asegura la razón de ser de las garantías" 2 . Esta concepción que hace la Corte debe ser entendida en el marco de nuestras afirmaciones anteriores, es decir, la reparación integral se constituye en el Ecuador como un derecho pleno, con igual valor y jerarquía que cualquier otro, cuya existencia, además, garantiza el objeto mismo de la existencia de las garantías.

${ }^{1}$ Corte Constitucional de Colombia, Sentencia T- 200 de 1993 M.P. Carlos Gaviria Díaz ${ }^{2}$ Corte Constitucional del Ecuador, Sentencia No. 050-15-SIS-CC, 14 de octubre de 2015

La reparación integral como derecho y principio: Estudio aplicado a las sentencias constitucionales de Machala, Ecuador 
En esa misma línea, algunos autores destacan que "la reparación es un deber del Estado y un derecho de las víctimas en el país”. (Villa \& Insuasty, 2015, pág. 425), no se alejan de lo que ocurre en el Ecuador. El Art. 88 de nuestra Carta Magna nos recuerda que cuando una jueza o juez constate la vulneración de derecho, además de declararla como tal en su sentencia, deberá también "ordenar la reparación integral, material e inmaterial”. Este mandato constitucional bien puede interpretarse como una orden directa a los administradores de justicia, pero más aún, se interpreta también como un derecho que se les reconoce a las personas, un derecho vivo, un derecho exigible, un derecho esencial y necesario para hacer verdadera justicia, no solo sancionando a los responsables, sino, además, adoptando medidas que le permitan a la víctima restituir, en lo posible, su situación al estado anterior a la vulneración.

La jurisprudencia de la Corte Constitucional nos permite entender que la reparación integral son aquellas "medidas que se deben adoptar para alcanzar la restitución y remediación de este, mejorando la situación de los agraviados volviendo la situación al estado anterior a la vulneración, promoviendo que se realicen reformas a nivel político, administrativo o de otra índole para evitar futuras vulneraciones"3.

Agrega la sentencia antes mencionada, que "el alcance de la reparación integral es ilimitado", lo cual se complementa con la Sentencia No. 004-13-SAN-CC, donde se señala que "dicha reparación debe alcanzar en mayor medida la restitutio in integrum restituyendo, compensando o indemnizando para reparar material e inmaterialmente el daño ocasionado" ${ }^{4}$.

Palabras más, palabras menos, se puede colegir que el derecho a la reparación integral se materializa a través de todas las medidas tendentes a la restitución y remediación total de cualquier derecho vulnerado y consecuentes afectaciones, por actuaciones públicas o privadas, en forma ilimitada, es decir, no ciñéndose únicamente a la restitución al estado anterior de la violación del derecho y/o al aspecto económico indemnizatorio sino también al plano inmaterial o extra-patrimonial, que, además, asegure el proyecto de vida, la satisfacción plena y la garantía de no repetición.

La Corte Constitucional del Ecuador guarda plena congruencia con los fallos de la Corte Interamericana de Derechos Humanos incluso reconociendo que la repa-

${ }^{3}$ Corte Constitucional de Ecuador, Sentencia No. 019-12-SEP-CC, 06 de junio del 2012

${ }^{4}$ Corte Constitucional del Ecuador, Sentencia No. 004-13-SAN-CC, 25 de junio del 2013

La reparación integral como derecho y principio: Estudio aplicado a las sentencias constitucionales de Machala, Ecuador 
ración integral debe ser entendida como un verdadero derecho constitucional que exige su garantías, asistiendole a toda persona afectada por el menoscabo de una derecho constitucional; es decir, si bien tiene por objeto o finalidad el garantizar la reparación plena de un derecho vulnerado, es un derecho en sí mismo a favor de las personas, que debe ser aplicado de manera obligatoria en todos los casos en los que se reconozca la existencia de la conculcación de un derecho reconocido en la Constitución.

Finalmente, si entendemos que la reparación integral es un derecho subjetivo en sí mismo, deben existir precedentes que garanticen su cumplimiento, como en efecto los tenemos. El fallo anteriormente citado del año 2013, recuerda la obligación de garantizar este derecho, y recoge el mandato contenido en el numeral 3 del Art. 86 de la Constitución, indicando que es correcto deducir que todas las sentencias de garantías jurisdiccionales "deben necesariamente contener la disposición de reparación integral en la parte resolutiva de la decisión constitucional."

\section{La reparación integral como principio}

La jurisprudencia de la Corte Constitucional señala, también, que reconoce a la reparación integral como un "principio orientador, internacionalmente reconocido y aceptado como norma consuetudinaria que opera para reparar consecuencias de

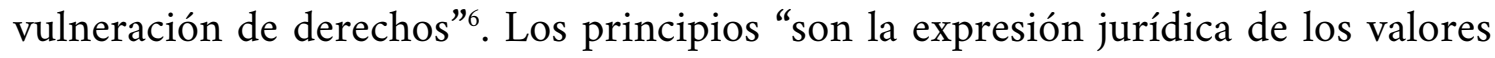
más altos del ordenamiento jurídico, que están radicados en el ser, que es fin y razón de ser del ordenamiento jurídico-constitucional, y allí es en donde reside en última instancia la fuerza de su exigibilidad” (Suárez J. , 2016, pág. 11).

En ese sentido, la concepción de reparación integral como principio previene de la necesidad de garantizar el efectivo ejercicio de los derechos de las personas, especialmente en lo que respecta a la restauración o el resarcimiento de los daños generados por la violación o vulneración de sus derechos.

El reconocimiento internacional al que se hace referencia, se encuentra desarrollado en el marco del Sistema Interamericano de Derechos Humanos, a través de los informes de la Comisión y/o de las Sentencias de la Corte. Así, en aplicación del derecho internacional de respetar y garantizar que se respeten los derechos huma- 
nos y las libertades fundamentales, cuando se produce la violación de un derecho humano se le da inmediatamente a la víctima el derecho a obtener una reparación y se impone al Estado no solo el deber de concederla, sino también la responsabilidad de prevenir las violaciones, investigarlas y tomar medidas apropiadas contra los autores; procurando de esa manera aliviar el sufrimiento de la o las víctimas y hacer justicia a través de la eliminación o corrección de los resultados de la vulneración, además de velar por la restitución, la indemnización, la rehabilitación, la satisfacción y las garantías de no repetición del acto u omisión a favor (Van Boven, 2017).

Como principio, la reparación integral, pretende presupuestar estándares sobre la medida en que los responsables de las violaciones de derechos constitucionales deben restaurar o restituir a las víctimas el daño que hubieren causado por sus actos, que no pueden estar instrumentados de forma total en las normas, sino que deben ser desarrollados a la luz de los postulados que sirven como orientación al juez de garantías, incluso con alcances ilimitados "siempre y cuando se proteja la justicia, los valores y principios consagrados en la Constitución”"

La reparación integral como principio debe tomar en consideración que, en la actualidad, el concepto de víctima "no se restringe a la condición pasiva del sujeto receptor del daño directo, también se incluye a los impactados indirectamente" (Vera, 2008, pág. 12)., donde se suman los colectivos humanos, las personas jurídicas y otras asociaciones, las personas afectadas por el delito aunque no se sientan victimizadas y a toda víctima independientemente de su tipo de relación con el victimario y de su propia conducta en el momento de sufrirlo ${ }^{8}$. Bajo esta premisa, la reparación integral no se relaciona de forma exclusiva con la persona a quien se violaron o vulneraron los derechos, sino, de todos a quienes de forma directa e indirecta se hubiera ilegalmente limitado o afectado su ejercicio.

Aceptar la idea de la reparación integral como principio, implica su reconocimiento ilimitado que le permite a los juzgadores desechar los estándares únicos en la solución de los casos, por el contrario, les da amplia libertad para adecuarlos de forma individual de acuerdo al caso concreto, recordando que su obligación consiste también en "buscar los mecanismos y medios adecuados para alcanzar el restablecimiento de los intereses afectados de las víctimas, tarea en la cual es impe-

${ }^{7}$ Corte Constitucional de Ecuador, Sentencia No. 019-12-SEP-CC, 06 de junio de 2012 ${ }^{8}$ Ibídem, p.739

La reparación integral como derecho y principio: Estudio aplicado a las sentencias constitucionales de Machala, Ecuador 
rativo hacer uso de todos los medios a su alcance, se trate de perjuicios materiales o inmateriales” (Sandoval, 2013, pág. 247). Villa Gómez \& Insuasty Rodríguez (2015) indican que:

el proceso de reparación es complejo en la medida en que no puede aparecer como una fórmula copiada y aplicada al pie de la letra, es necesario, además, que este se haga dentro de una lectura del contexto, responsable, profunda y compleja, que considere a los actores protagonistas (las víctimas y las comunidades azotadas por el conflicto), las temporalidades y las necesidades propias de la gente, apuntando realmente a la satisfacción de las mismas (Villa \& Insuasty, 2015, pág. 428).

En esa misma línea, la Corte Constitucional del Ecuador estableció que:

Los jueces constitucionales se encuentran en la obligación de ser creativos al momento de determinar las medidas de reparación integral que dentro de cada caso puesto a su conocimiento deban ser establecidas, a fin de que la garantía jurisdiccional sea efectiva y cumpla su objetivo constitucional (...) De esta forma, los operadores de justicia deben asumir un rol activo a la hora de resolver una garantía constitucional, buscando los medios más eficaces de reparación que cada caso requiera, sin que la Ley Orgánica de Garantías Jurisdiccionales y Control Constitucional sea aplicada de forma restrictiva para ello 9 .

Al final, podemos aceptar la concepción de la reparación integral como un principio orientador con alcances ilimitados, dado que el carácter abstracto que se ha dado a su instrumentalización en el sistema de justicia, no impide en forma alguna que este cumpla con su objetivo de restituir o restaurar el daño sufrido por la violación de un derecho.

Entonces, la integración del principio de reparación integral en el sistema de justicia ecuatoriano, presupuesta a que su aplicación no se rija de forma estricta a lo establecido en la Ley Orgánica de Garantías Jurisdiccionales y Control Constitucional, puesto que la aplicación matemática de la normativa, implicaría reducir inconstitucionalmente el ejercicio del derecho a la reparación integral, y en este mismo sentido, restringir a los jueces constitucionales su aplicación como tal, alejándonos de la lógica de que "el objetivo de la justicia constitucional es el de perfeccionar la

${ }^{9}$ Corte Constitucional de Ecuador, Sentencia No. 146-14-SEP-CC, 27 de octubre de 2014

La reparación integral como derecho y principio: Estudio aplicado a las sentencias constitucionales de Machala, Ecuador 
democracia y alcanzar todos los ideales plasmados en la Constitución”. (García, 2013, pág. 18)

Para la aplicación de este principio, una publicación de la propia Corte Constitucional del año 2018 denominada "Reparación Integral" (Ruiz, Aguirre, \& Ron, 2018). Nos explica las diferentes formas que tienen las juezas y jueces para llevarlo a cabo. Se diferencian las medidas de restitución como dejar sin efecto una sentencia, realizar nuevamente un proceso judicial, reincorporar a la víctima a su cargo, restablecer la libertad o restituir bienes y valores; medidas de rehabilitación; medidas de satisfacción como disculpas públicas, medidas de concientización y memoria o la publicación de los fallos; medidas de obligación de investigar los hechos, además de determinar y sancionar a los responsables; medidas de reparación material; y, medidas que garanticen la no repetición del daño como reformas normativas, capacitaciones al personal o la adopción de medidas administrativas.

\section{Aplicación de los precedentes de la Corte Constitucional en la Justicia Constitucional ordinaria: casos relevantes de las unidades judiciales con sede en el Cantón Machala y salas de la corte provin- cial de El Oro, en los años 2016 y 2017}

Siguiendo la lógica del método deductivo, en cuyo razonamiento "primero deben conocerse las premisas para que pueda llegarse a una conclusión” (Dávila, 2006, pág. 186), se consideró importante identificar los hechos del caso, la pretensión, el problema jurídico y el fallo, además, es indispensable verificar la forma en que los parámetros de la Corte Constitucional del Ecuador están siendo aplicados en la justicia constitucional ordinaria de primero y segundo nivel, para lo cual se pudo acceder al cien por ciento de las sentencias de garantías jurisdiccionales que fueron emitidas en la ciudad de Machala en los años 2016 y 2017, las mismas fueron sometidas al análisis jurídico y estadístico dentro de nuestra investigación. Machala, es la capital de la Provincia de El Oro, provincia ubicada al sur del Ecuador y que tiene frontera con el hermano país peruano. Tiene una población que sobrepasa los doscientos cuarenta y cinco mil habitantes según los datos proporcionados por el (Instituto Nacional de Estadíticas y Censos., 2010) que la ubica como la quinta ciudad más poblada del Ecuador y que fue escogida por los autores con el objetivo de hacer un análisis local al pertenecerse a la Universidad Técnica de Machala, de la misma ciudad.

La reparación integral como derecho y principio: Estudio aplicado a las sentencias constitucionales de Machala, Ecuador 
Por otro lado, a modo de aclaración, en el Ecuador todos los derechos son justiciables, para lo cual existen diferentes mecanismos que se ejercen a través de garantías primerias y secundarias que contempla nuestro modelo constitucional. Si bien existe un modelo de control concentrado de constitucionalidad ejercitado por un órgano autónomo y superior denominado Corte Constitucional, ésta conoce las "acciones por incumplimiento", "acciones de incumplimiento", y "acciones extraordinarias de protección" contra las sentencias de la justicia ordinaria y justicia indígena, es decir, llegan a su conocimiento sólo cuando lo previo ha fracasado, por lo tanto, la mayor carga procesal de justicia constitucional la tienen los jueces de primera instancia, quienes conocen y resuelven "acciones de protección", "acciones de hábeas corpus", "acciones de hábeas data" y "acciones de acceso a la información pública", es decir, los jueces de la justicia ordinaria se transforman en jueces constitucionales al momento de conocer una acción de garantías jurisdiccionales.

En esa línea de ideas, según la investigación realizada, entre los años 2016 y 2017, en la ciudad de Machala se conocieron un total de doscientas tres (203) acciones de garantías jurisdiccionales, entiéndase: acciones de protección de derechos, petición de medidas cautelares autónomas, acciones de acceso a la información, hábeas data y hábeas corpus. Ciento once (111) acciones jurisdiccionales fueron presentadas en el año 2016 y noventa y dos (92) en el año 2017, conforme lo refleja la siguiente figura:

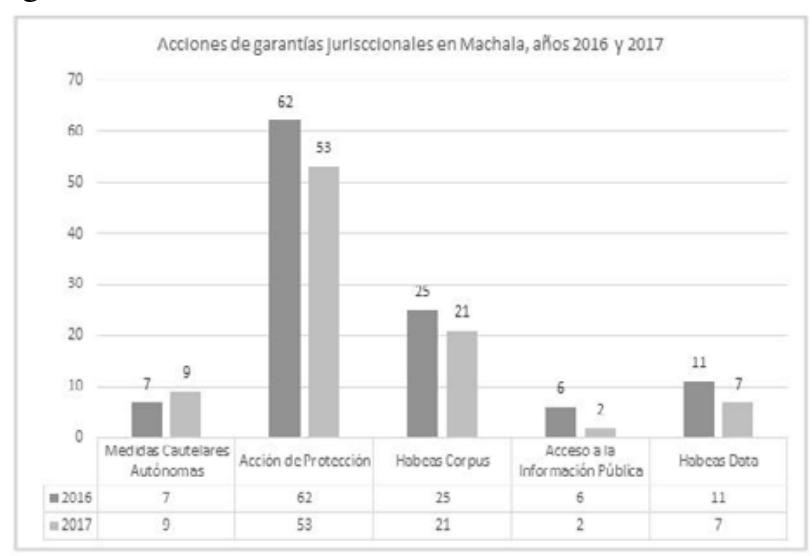

Figura 1. Fuente: Consejo de la Judicatura - El Oro Elaborado por: Los autores

De éstas acciones, muy pocas fueron admitidas y un gran número de acciones fue inadmitida o declarada sin lugar, a lo que sumamos -y hemos dado la categoría 
de "otro"- un pequeño número de demandas que por diferentes razones fueron archivadas, ya sea por allanamientos, desistimientos o, inclusive, algunas que nunca concluyeron su trámite. En el año 2016 se aceptaron el 18,02\% de las acciones jurisdiccionales presentadas y se negaron el 52,25\%, sumado el 29,73\% de los casos que fueron archivados por otros motivos; mientras que en el año 2017 se aceptaron el $18,48 \%$ y se negaron el $60,87 \%$, sumado el $20,65 \%$ de casos archivados o desestimados. Es decir, tanto en el año 2016 como en el 2017 el porcentaje de acciones admitidas no llega ni siquiera al veinte por ciento, tal y como reflejamos en los siguientes dos cuadros:

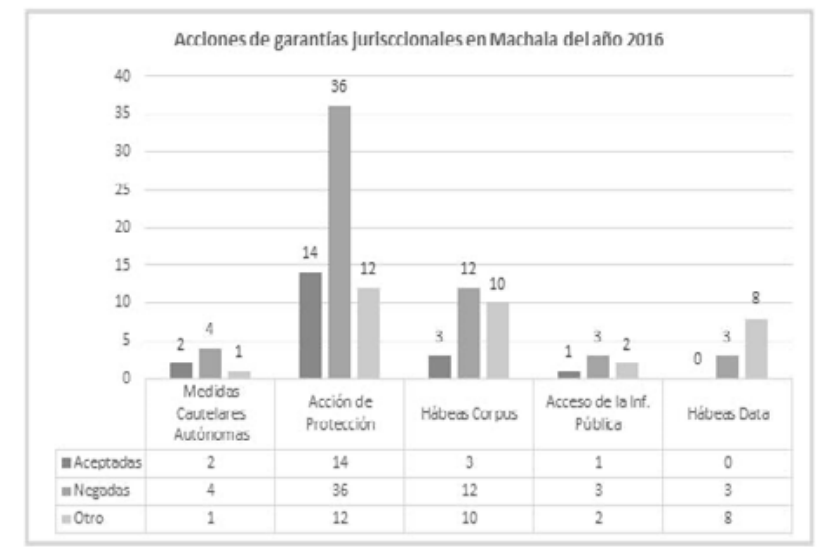

Figura 2. Fuente: Consejo de la Judicatura - El Oro Elaborado por: Los autores

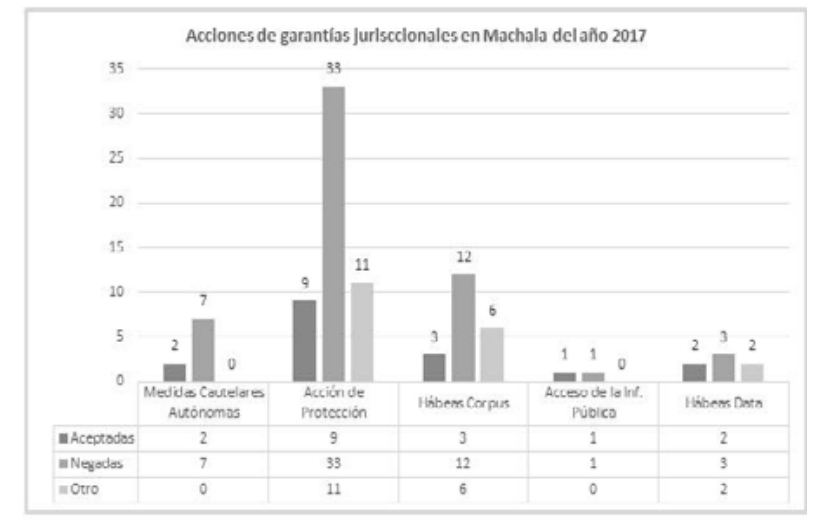

Figura 3. Fuente: Consejo de la Judicatura - El Oro Elaborado por: Los autores

La reparación integral como derecho y principio: Estudio aplicado a las sentencias constitucionales de Machala, Ecuador 
Con estos datos, al momento de hacer el proceso de revisión de las sentencias emitidas por las Unidades Judiciales con sede en el Cantón Machala y Corte Provincial de El Oro y evaluar si la aplicación de la reparación integral en la justicia constitucional ordinaria han observado tanto las directrices impartidas por la Corte Constitucional así como los parámetros establecidos por la Corte Interamericana de Derechos Humanos, pudimos encontrar algunos fallos que marcaban la diferencia en cuanto a las formas de reparación que los jueces utilizaron, evidenciando de alguna forma aquel factor de creatividad que se les exige para lograr una reparación tanto material como inmaterial. A continuación, detallamos las formas de reparación adoptadas:

En el Caso No. 07333-2016-01440, donde una lista había sido descalificada de unas elecciones gremiales vulnerando sus derechos de participación, la Jueza Constitucional de primera instancia resolvió aceptar la acción de protección de protección propuesta, y ordenó como de medidas de reparación integral:

(...) disponiéndose como REPARACIÓN INTEGRAL, que los accionados convoquen a nuevas elecciones para elegir a los miembros del Consejo Directivo de la XXX, estableciendo las normas claras que van a regir el proceso electoral inclusive resolver con anticipación la determinación de la fecha de la conformación del padrón electoral, esto es, se precise la fecha de corte en el pago de las cuotas de los afiliados, para que con ello, quienes deseen postularse estén al día en sus cuotas, dando cumplimiento a lo establecido en el Art. 83 de la Constitución de la República del Ecuador, referente a los deberes y responsabilidades de las ecuatorianas y los ecuatorianos, de participar en la vida política, cívica y comunitaria, de manera honesta y transparente $(. .$.

En un caso similar de No. 07283-2016-00052, donde se demandaba la vulneración al debido proceso y, consecuentemente, a los derechos de participación en unas elecciones universitarias por cuanto se había impuesto una sanción sin que previamente se haya agotado el debido proceso impidiendo el ejercicio del derecho a la defensa, la Jueza Constitucional de primera instancia, de la Unidad Judicial de Garantías Penales con sede en el Cantón Machala, resolvió aceptar la acción de protección de protección propuesta, y ordenó como de medidas de reparación integral las siguientes:

La reparación integral como derecho y principio: Estudio aplicado a las sentencias constitucionales de Machala, Ecuador 
(...) y como RESTITUCIÓN DEL DERECHO: 1.- se deja sin efecto la ejecución de sanción en contra del accionante, contenida en el oficio NT-TEFAL- NXXX, emitido el día 29 d enero del 2016 que contiene la suspensión de un día de campaña de XXX, de la cual oportunamente la suscrita jueza emitió la medida cautelar para que dicho movimiento pueda ejercer el derecho de realizar campaña a partir de la hora que fueron notificados. 2.- Se dispone en el Reglamento de Elecciones para renovar el directorio de XXX se incorpore un capitulo en el que se norme el proceso sancionatorio a aplicar en el caso de vulneración de dichas normas, con el fin de garantizar la seguridad jurídica y el derecho a la defensa de quienes pudieran incurrir en infracciones, obligación que quedó en conocimiento del accionado desde que la suscrita emitió su sentencia de forma verbal en audiencia para la presente y futuros procesos de elección... dispongo como medida de reparación que el tribunal electoral a través de su representante pida disculpas públicas al accionante por habérsele privado de dicho derecho, a través de un medio de comunicación, de cuyo cumplimiento que se presentará constancia física en esta unidad judicial... Para el seguimiento del cumplimiento de la presente sentencia se delega al defensor del pueblo de esta ciudad de Machala de conformidad al Art. 21 de la LOGJCC, a quien se le hará conocer mediante oficio con copia certificada de ésta resolución (...)

En el mismo caso, pero en segunda instancia, la Sala de Familia, Mujer, Niñez y Adolescencia de la Corte Provincial de Justicia de El Oro indicó:

(...) y como RESTITUCIÓN de los derechos vulnerados, reconocidos en el Art. 76.7.a), b), c), h), l) de la Constitución de la República del Ecuador, se deja sin efecto la sanción en contra del accionante, contenida en el oficio NT-TEFAL- NXXX, emitido el día 29 de enero del 2016, que contiene la suspensión de un día de campaña de integración Universitaria en las elecciones estudiantiles. Como reparación integral al Movimiento XXX, se dispone que el Tribunal Electoral a través de su Presidente, pida disculpas por escrito al accionante, en cuyo texto se incluirá las garantías de que el hecho no se repetirá, de cuyo cumplimiento que se dejará constancia procesalmente (...)

En los casos transcritos No. 07333-2016-01440 y No. 07283-2016-00052 podemos observar que los jueces constitucionales de primer nivel de las unidades judiciales con sede en el Cantón Machala no agotan su fallos con la declaratoria de vulneración de derechos y la restitución de la situación al estado anterior, sino que

La reparación integral como derecho y principio: Estudio aplicado a las sentencias constitucionales de Machala, Ecuador 
además, acoge el criterio de la Corte Constitucional respecto de la garantía de no repetición ${ }^{10}$ con el objeto de que no se vuelvan a verificar las acciones transgresoras, como ocurre en estos casos en los que ordenan a la institución pública demandada ha accionar su capacidad legislativa para que, en primera instancia, reglamente todo el proceso de elecciones incluyendo a la parte operativa - administrativa detallando minuciosamente el proceso eleccionario, y, en segunda instancia, modifique el Reglamento de Elecciones existente incorporando un capítulo en el que coste el régimen disciplinario; con la finalidad de garantizar tanto la seguridad jurídica y el derecho a la defensa como también asegurar completamente el derecho a elegir y ser elegido no solo para los casos tratados sino también para las elecciones futuras con los mismos o nuevos actores políticos.

En el Caso No. 07205-2016-00532, que gira en torno al trato discriminatorio y racista del Teniente Coronel XXX en contra del Cabo XXX, su subordinado, que incomprensiblemente fue negado por la Jueza Constitucional de primera instancia de la Unidad Judicial de la Familia, Mujer, Niñez, Adolescencia y Adolescentes Infractores con sede en el Cantón Machala, bajo el horroroso argumento de que "el accionante no ha sido objeto de discriminación, al no haber sido separado de sus funciones, $\mathrm{y}$ al no haber sido restringido sus derechos (entiendo, laborales o remunerativos) como servidor Público", en la segunda instancia, sustanciada en la Sala de la Familia, Mujer, Niñez y Adolescencia de la Corte Provincial de El Oro se corrige los errores y resolvió aceptar la acción de protección de protección propuesta, y ordenó como de medidas de reparación integral:

(...) ordenando como reparación integral, lo siguiente: 1.- Se prohíbe al Teniente Coronel XXX, se vuelva a referir en términos racistas o discriminatorios en contra del Cabo XXX ya sea de manera pública o privada, debiendo respetar la igualdad de todos sin distinción ante la ley; y, 2.- Que el Teniente Coronel XXX, pida disculpas públicas al Cabo XXX, en un acto castrense donde estén presentes la mayoría de los integrantes de la Brigada a la que se pertenece; para su cumplimiento se oficiará al Jefe de la Brigada de Infantería Motorizada XXX de El Oro, quien establecerá el día y hora para dicho acto que se llevará a efecto dentro de los 15 días contados a partir de su notificación; ceremonia que con-

\footnotetext{
${ }^{10}$ Véase: Corte Constitucional del Ecuador, Sentencia No. 146-14-SEP-CC, 01 de octubre de 2014
}

La reparación integral como derecho y principio: Estudio aplicado a las sentencias constitucionales de Machala, Ecuador 
tará con la presencia del Defensor del Pueblo de El Oro, quien verificará se cumpla en la forma ordenada en esta sentencia e informe a la Jueza de primer nivel, para lo cual es obligación del jefe de la Brigada hacer conocer el día y hora en que se efectuará el acto $(. .$.

En este caso, nótese la forma en que el Juez de Primera Instancia, para negar la acción constitucional, sólo analizó las circunstancias y derechos de carácter laboral que se materializan en el aspecto económico y que son susceptibles de cuantificación exacta; error que fue corregido por los jueces de apelación en la Sala de la Corte Provincial de Justicia de El Oro, ya que en segunda instancia se analizó también la afectación psicológica y moral de la cual fue objeto el accionante y que no tiene necesariamente un base reglamentaria interna de la institución a la cual pertenece el demandado o una fácil apreciación monetaria, cumpliendo de esta forma con los parámetros de la Corte Constitucional y de la Corte Interamericana de Derechos Humanos, ordenando que se ofrezcan disculpas públicas, las mismas que se encuentran comprendidas dentro de las medidas de satisfacción de carácter simbólico ${ }^{11}$.

La reparación, entonces, no solo que guarda atención e interés en la materialidad de las cosas, sino también en medidas inmateriales que buscan la íntegra reparación del ser humano, a fin de resarcir los daños ocasionados a los derechos como la honra, la identidad, la integridad psicológica, igualdad y no discriminación, entre otros.

En el Caso No. 07205-2016-01459, donde una asociación de comuneros comparece con el objeto que se les entregue formalmente en custodia un área de los salitrales de la zona de playa para asegurar su preservación y conservación en estado natural y libre de cualquier amenaza destructiva de su frágil ecosistema o apropiación arbitraria del mismo, la Jueza Constitucional de primera instancia de la Unidad Judicial de la Familia, Mujer, Niñez, Adolescencia y Adolescentes Infractores con sede en el Cantón Machala,, resolvió aceptar la acción de protección de protección propuesta, y ordenó como de medidas de reparación integral:

(...) no obstante de ello esta autoridad se encuentra en la obligación de precautelar y velar por que no se realicen actos indebidos sin las respectivas autorizaciones de la entidades respectivas, en virtud de aquello se ordena: QUE SE PARALICE la construcción de la piscina camaronera que se encuentra en

\footnotetext{
${ }^{11}$ Véase: Corte Constitucional del Ecuador, Sentencia No. 273-15-SEP-CC, 19 de agosto de 2015
}

La reparación integral como derecho y principio: Estudio aplicado a las sentencias constitucionales de Machala, Ecuador 
el sitio XXX, hasta que los mencionados comuneros o personas que habitan en el sitio $X X X$, relacionadas e interesadas con esa actividad pudiesen obtener los permisos respectivos... 4.- Dentro del expediente no se cuenta con una cuantificación de daños por lo que se dispone que el Ministerio de Medio Ambiente con sede en esta Provincia, realice todas las inspecciones necesarias, por cuanto son ellos a quienes les corresponde, en el momento de determinar que exista alguna afectación y en el presente caso por haber observado que se continúan realizando labores se encuentran en la obligación de intervenir en forma inmediata en el sitio XXX, a efectos que determine si existe algún otro tipo de afectación, cuantifique daños y se encargue de disponer el resarcimiento de daños ocasionados. 5.Remítase fotocopias certificadas, de las piezas procesales relevantes e informes realizados, al Ministerio de Acuacultura para que proceda a realizar la intervención directa y las investigaciones necesarias a efectos de precautelar que se no se construya en forma indebida piscinas camaroneras. 6.- Con el objeto de precautelar que la remoción de suelo o las actuaciones que han realizado los gestores del presunto daño ambiental no se configure en un delito, se dispone que se remita fotocopias certificadas de las mismas piezas procesales dispuesta en el numeral precedente, a la fiscalía de El Oro, para que sea esta entidad las que investigue determine si existe el cometimiento de algún delito y quienes son los responsables (...)

A lo largo de sus líneas jurisprudenciales, la Corte Constitucional también ha hecho eco de la obligación de investigar, establecer responsables y sancionar como parte de la reparación integral, lo cual está ligado al derecho a la verdad de las víctimas ${ }^{12}$, en el cual no solo que se incluye el resarcimiento monetario sino también el acceso y materialización del derecho a la justicia y al conocimiento de la verdad objetiva o por lo menos judicial. En la sentencia citada, la Unidad Judicial de la Familia, Mujer, Niñez, Adolescencia y Adolescentes Infractores con sede en el Cantón Machala acoge el parámetro de la Corte Constitucional y no solo que ordena la suspensión de los hechos vulneradores sino que permite que los accionantes accedan a los permisos que requieren para proteger sus derechos, librándose de los efectos de cualquier plazo establecido en la ley, por tanto, eliminando cualquier impedimento legal que pudiere obstaculizar la reparación integral y el derecho a la verdad en todas sus

\footnotetext{
${ }^{12}$ Véase: Corte Constitucional, Sentencia No. 163-12-SEP-CC, 19 de abril de 2012
}

La reparación integral como derecho y principio: Estudio aplicado a las sentencias constitucionales de Machala, Ecuador 
facetas; además, se dispone intervenciones directas al Ministerio de Acuacultura y al Ministerio del Medio Ambiente, con el ánimo de investigar y sancionar, incluso en el ámbito penal, debiendo remitirse el caso a la Fiscalía General del Estado.

En el Caso No. 07283-2016-00360, donde el señor XXX demanda al IESS con el objeto de acceder a los beneficios de las prestaciones de jubilación en virtud de haber cumplido con los requisitos establecidos en la Ley, recibiendo una negativa por parte del accionado por cuanto su empleador registra aportes pendientes de pago, el Juez Constitucional de primera instancia, de la Unidad Judicial de Garantías Penales con sede en el Cantón Machala, resolvió aceptar la acción de protección de protección propuesta, lo cual fue ratificado en segunda instancia en la Sala de lo Civil de la Corte Provincial de El Oro, y ordenó como de medidas de reparación integral:

(...) como Restitución del derecho vulnerado dispongo: 1.- Que el Instituto Ecuatoriano de Seguridad Social de El Oro, formalice y dé el trámite que corresponde a la solicitud de Jubilación por Vejez, presentada por el accionante señor XXX, por cuanto cumple con lo determinado en el Art. 188, de la Ley de Seguridad Social (...) En el Caso No. 07371-2016-00744, el Juez Constitucional de primera instancia de la Unidad Judicial de Trabajo con sede en el Cantón Machala, con fundamento en una inspección in situ donde recogió versiones de moradores que no se sentían afectados, negó el pedido de la señora XXX que demandaba la vulneración de su derecho a la salud, el cual se encontraba afectado debido a los desechos de los derivados de hidrocarburos de un taller mecánico artesanal ubicado cerca de su domicilio, fallo que posteriormente fue revocado en segunda instancia por los jueces de la Sala de lo Civil de la Corte Provincial de El Oro, quienes resolvieron aceptar la acción de protección de protección propuesta, y ordenaron como de medidas de reparación integral:

(...) Se Acepta el recurso de apelación interpuesto por la accionante señora XXX disponiendo: Que el Gobierno Autónomo Descentralizado Municipal del cantón Machala, en el plazo de SESENTA DIAS, reubique en una zona destinada para estas actividades de mecánica automotriz al Taller Automotriz del señor XXX ubicado en las calles XXX de la Ciudadela XXX de esta Ciudad de Machala, de conformidad como lo establecen los Arts. 54, 55 y 466 de la COOTAD (...)

La reparación integral como derecho y principio: Estudio aplicado a las sentencias constitucionales de Machala, Ecuador 
En estos dos últimos casos, en el que se observa como denominador común que la omisión de los demandados de cumplir la ley provoca el no poder ejercer el derecho a la jubilación y el derecho a la salud de los accionantes, respectivamente; podemos observar la forma en que los Jueces del cantón Machala disponen la adopción de medidas administrativas específicas, tanto al Instituto Ecuatoriano de Seguridad Social al continuar con el trámite de jubilación, pese a que formalmente el afiliado no cumplía con el número de aporte patronales por la falta de pago del empleador al IESS o como ocurre con el Gobierno Autónomo Descentralizado Municipal con la reubicación de un negocio, lo cual permite verificar que en la justicia constitucional los jueces no deben limitarse al análisis del cumplimiento rígido de una norma sino que deben actuar inclusive por sobre estos formalismos en búsqueda de la justicia a través de la reparación integral de la víctima, ratificando su carácter de derecho ilimitado y protector de la justicia, los valores y de los principios consagrados en la Constitución de la República tal y como también lo ha hecho la Corte Constitucional adoptando medidas que logren reparar integralmente los daños causados (Ruiz, Aguirre, \& Ávila, 2016).

Si entendemos a la reparación integral como principio orientador, como en efecto se lo hace, cada reparación debe adaptarse a cada caso, de forma ingeniosa y adecuada afirma la Corte, razón por la cual, consideramos oportunas las medidas adoptadas en las sentencias citadas, dando cumplimiento a los parámetros.

Varios doctrinarios coinciden que "en el campo de la justicia y concretamente en las sentencias es posible realizar un análisis de la personalidad del juez". (Escobar, 2007, pág. 296), sin embargo, en el sistema de justicia constitucional ecuatoriana aun es difícil precisar en ese análisis, ya que es reciente la forma con que va creciendo la actividad judicial en esta rama y con una dosis interesante de lo que se conoce como activismo judicial, en tanto y cuanto "atañe a una manera específica en la que se implican los jueces en los asuntos públicos”. (Feoli, 2015, pág. 182), en donde, si bien la mayoría de demandas son archivadas o inadmitidas, podemos observar importantes iniciativas de los jueces en procura de la defensa de los derechos constitucionales de los peticionarios.

De las sentencias citadas, se aprecia la preocupación del juez constitucional, de las unidades judiciales con sede en el Cantón Machala y Salas de la Corte Provincial de El Oro, de no solo cumplir con las directrices de la Corte Constitucional y parámetros de la Corte Interamericana de Derechos Humanos sino también de la existencia de ese factor de creatividad que tiene como prioridad lograr remediar

La reparación integral como derecho y principio: Estudio aplicado a las sentencias constitucionales de Machala, Ecuador 
los daños causados, así como la intención de prevenir nuevos hechos similares. Las reparaciones integrales incluyeron la orden de pedir disculpas públicas, reformar Reglamentos, reubicar establecimientos e, incluso, suspender la explotación camaronera en una zona de playa con el objeto de remediar los daños ambientales ocasionados. En fin, podemos afirmar que la justicia constitucional ordinaria va dando muestras de su clara intención de ajustarse a la corriente garantista que exige el nuevo modelo constitucional ecuatoriano.

\section{Conclusiones}

1. Según su jurisprudencia, en la noción de la Corte Constitucional se reconoce a la reparación integral como consecuencia lógica de las garantías jurisdiccionales, considerándola como un derecho plenamente exigible de las personas y como un principio orientador con alcances ilimitados, que exige al juez constitucional ser creativo al momento de determinar las medidas de reparación integral, a fin de que cada una de las garantías jurisdiccionales sean efectivas y cumplan su objetivo constitucional.

2. La reparación integral como derecho debe entenderse como aquella facultad y expectativa que tienen las personas, en respuesta directa a una vulneración de sus derechos, o de sus familiares cuando el afectado no pueda hacerlo directamente, para exigir al Estado que, una vez reconocida dicha vulneración por el órgano jurisdiccional competente, sea resarcido de forma material e inmaterial, patrimonial y extrapatrimonial, asegurando su no repetición.

3. La reparación integral como principio supera las limitaciones normativas y permite la aproximación a la plena restauración de los derechos de las personas a quienes se hubiera vulnerado un derecho constitucional, instituyendo en el derecho nacional e internacional, estándares y parámetros mínimos como forma de reparación, y a su vez, permitiendo que su aplicación no se limite a normativas infraconstitucionales.

4. La justicia constitucional ordinaria en el Ecuador apuesta por su adaptación a la corriente garantista implementada con la Constitución de 2008, mediante la aplicación de las directrices impartidas por la Corte Constitucional a través de su jurisprudencia, siendo creativos y diversos al momento de reparar integralmente las vulneraciones de derechos, incluso anticipando y/o previniendo casos futuros

La reparación integral como derecho y principio: Estudio aplicado a las sentencias constitucionales de Machala, Ecuador 
con la finalidad dejar a salvo los derechos constitucionales de los demandantes y ciudadanos en general.

5. En nuestra investigación, pudimos observar algunos fallos donde los jueces de las Unidades Judiciales del Cantón Machala, y sus superiores en las Salas Especializadas de la Corte Provincial de Justicia de El Oro, comprenden y acogen los criterios y los parámetros de la Corte Constitucional sobre la reparación integral, sin embargo, solo representan pequeños avances debido al mínimo dieciocho por ciento (18\%) de garantías jurisdiccionales que son aceptadas y, entre las aceptadas, son excepcionales los casos donde los jueces reparan de forma creativa para la plena satisfacción de los derechos. Podríamos decir que en el Ecuador vamos por buen camino, pero seguimos ahí, todavía en el camino.

\section{Referencias bibliográficas}

Álvarez, I. (2001). Sobre el concepto de derecho subjetivo de Hans Kelsen. Boletín de la Facultad de Derecho UNED, 17, 27-74. Obtenido de http://e-spacio.uned.es/ fez/view/bibliuned:BFD-2001-17-C830506E

Cárdenas, M., \& Suárez, I. (2014). Aplicación de los criterios de reparación de la jurisprudencia de la Corte Interamericana de Derechos Humanos en las sentencias del Consejo de Estado colombiano. Opinión Jurídica, 13(26), 33-48. Obtenido de https://www.redalyc.org/articulo.oa?id=94535421003

Cepeda, E., \& Ramírez, C. (2016). Reparación integral de niños víctimas de los delitos sexuales en Colombia. restricciones y posibilidades a la luz de la jurisprudencia. Revista Chilena de Derecho, 43(3), 1057-1080. Obtenido de https:// scielo.conicyt.cl/pdf/rchilder/v43n3/art12.pdf

Dávila, G. (2006). El razonamiento inductivo y deductivo dentro del proceso investigativo en ciencias experimentales y sociales. Laurus, 12 (Ext), 180-205. Obtenido de https://www.redalyc.org/articulo.oa?id=76109911

Escobar, L. (2007). La actividad judicial. El texto frente a la realidad. Vniversitas(114), 291-317. Obtenido de https://www.redalyc.org/articulo.oa?id=82511410

La reparación integral como derecho y principio: Estudio aplicado a las sentencias constitucionales de Machala, Ecuador 
Feoli, M. (2015). El nuevo protagonismo de los jueces: una propuesta para el análisis del activismo judicial. Revista de Derecho - Universidad Católica del Norte, 22 (2), 173-198. Obtenido de https://www.redalyc.org/articulo.oa?id=371043382006

García, L. (2013). ¿Ideal democrático? Del activismo judicial a la constitucionalización del derecho. Civilizar. Ciencias Sociales y Humanas, 13(25), 17-32. Obtenido de https://www.redalyc.org/articulo.oa?id=100230029002

Instituto Nacional de Estadíticas y Censos. (2010). Población y Demografía. Obtenido de https://www.ecuadorencifras.gob.ec/censo-de-poblacion-y-vivienda/

Ruiz, A., Aguirre, P., \& Ávila, D. (2016). Desarrollo jurisprudencial de la primera Corte Constitucional: Periodo noviembre de 2012 - noviembre de 2015. Quito: Corte Constitucional del Ecuador.

Ruiz, A., Aguirre, P., \& Ron, X. (2018). Reparación integral: análisis a partir de la jurisprudencia de la Corte Constitucional del Ecuador. Quito: Corte Constitucional del Ecuador .

Sandoval, D. (2013). Reparación integral y responsabilidad civil: el concepto de reparación integral y su vigencia en los daños extrapatrimoniales a la persona como garantía de los derechos de la víctima. Revista de Derecho Privado(25), 237-273. Obtenido de https://www.redalyc.org/pdf/4175/417537443010.pdf

Suárez, J. (2016). El fundamento de los principios jurídicos: una cuestión problemática. Civilizar Ciencias Sociales y Humanas, 16(30), 51-61. Obtenido de https://www.redalyc.org/pdf/1002/100246672002.pdf

Van Boven, T. (2017). Estudio relativo al derecho de restitución, indemnización y rehabilitación a las víctimas de vilaciones flagrantes de los derechos humanos y las libertades fundamentales.

Vera, D. (2008). Desarrollo internacional de un concepto de reparación a las víctimas de violaciones a los derechos humanos e infracciones al derecho internacional humanitario: complementos a la perspectiva de la ONU. Papel Político, $12(2), 739-773$.

Villa, J., \& Insuasty, A. (2015). Significados en torno a la reparación, la ayuda humanitaria, la indemnización y la restitución en víctimas del conflicto armado en el municipio de San Carlos. El Ágora USB, 15(2), 419-445. doi: $10.21500 / 16578031.1623$

La reparación integral como derecho y principio: Estudio aplicado a las sentencias constitucionales de Machala, Ecuador 


\section{Jurisprudencia citada}

Aguilar con Municipio de Machala (2016): Sala de lo Civil de la Corte Provincial de El Oro, 31 de enero de 2017. Sentencia dentro del Caso No. 07371-201600744. En http://consultas.funcionjudicial.gob.ec/

Centro de Desarrollo Comunitario de Las Casitas "CEDECO" con Ministerio de Ambiente (2016): Unidad Judicial de Familia, Mujer, Niñez, Adolescencia y Adolescentes Infractores con sede en el Cantón Machala, 02 de septiembre de 2016. Sentencia dentro del Caso No. 07205-2016-01459. En http://consultas.funcionjudicial.gob.ec/

Cortez con Cabrera (2016): Sala de Familia, Mujer, Niñez y Adolescencia de la Corte Provincial de El Oro, 22 de marzo de 2016. Sentencia dentro del Caso No. 07205-2016-00532. En http://consultas.funcionjudicial.gob.ec/

Hidalgo Martínez, Norma Guadalupe (2012): Corte Constitucional, 06 de junio de 2012. Acción Extraordinaria de Protección. Sentencia No. 019-12-SEP-CC, dentro del Caso No. 0440-09-EP, publicada en el Registro Oficial Suplemento No. 718 .

Martínez Rosero, Leonel Segundo (2015): Corte Constitucional, 14 de octubre de 2015. Incumplimiento de Sentencias y Dictámenes. Sentencia No. 050-15-SISCC, dentro del Caso No. 0059-10-IS, publicada en el Registro Oficial Suplemento No. 607.

Masabanda Espin, Claudio Demetrio (2013): Corte Constitucional, 25 de junio de 2013. Acción por Incumplimiento. Sentencia No. 004-13-SAN-CC, dentro del Caso No. 0015-10-AN, publicada en el Registro Oficial Suplemento No. 22.

Movimiento Integración Universitaria con Tribunal de Elecciones (2016): Unidad Judicial de Garantías Penales con sede en el Cantón Machala, 05 de febrero de 2016. Sentencia dentro del Caso No. 07283-2016-00052. En http://consultas. funcionjudicial.gob.ec/

Muñoz Vélez, Fausto Enrique (2015): Corte Constitucional del Ecuador, 19 de agosto de 2015. Acción Extraordinaria de Protección. Sentencia No. 273-15-SEP-CC, dentro del Caso No. 0528-11-EP, publicada en el Registro Oficial Suplemento No. 629. 
Palacios Palacios, Víctor Raúl (2014): Corte Constitucional, 5 de diciembre de 2014. Incumplimiento de Sentencias y Dictámenes. Sentencia No. 024-14-SIS-CC, dentro del Caso No. 0023-12-IS (Regla Jurisprudencial), publicada en el Registro Oficial Suplemento No. 390.

Ramírez Enríquez, Luis Jorge (2014): Corte Constitucional, 27 de octubre de 2014. Acción Extraordinaria de Protección. Sentencia No. 146-14-SEP-CC, dentro del Caso No. 1773-11-EP, publicada en el Registro Oficial Suplemento No. 362.

Sandoval Viana, José Ricardo (2016): Corte Constitucional, 15 de marzo de 2016. Incumplimiento de Sentencias y Dictámenes. Sentencia No. 060-15-SIS-CC, dentro del Caso No. 0094-11-IS, publicado en el Registro Oficial Suplemento No. 712.

Sotomayor con Cámara de Comercio de Machala (2016): Unidad Judicial Civil con sede en el Cantón Machala, 07 de junio de 2016. Sentencia dentro del caso No. 07333-2016-01440. En http://consultas.funcionjudicial.gob.ec/

Tobar con Instituto Ecuatoriano de Seguridad Social (2016): Unidad Judicial de Garantías Penales con sede en el Cantón Machala, 29 de agosto de 2016. Sentencia dentro del Caso No. 07283-2016-00360. En http://consultas.funcionjudicial. gob.ec/

Zaldumbide Garaycoa, Andrés (2012): Corte Constitucional, 19 de abril de 2012. Acción Extraordinaria de Protección. Sentencia No. 163-12-SEP-CC, dentro del Caso N. ${ }^{\circ}$ 0710-10-EP, publicada en el Registro Oficial Suplemento 756. 

Universidad Técnica de Machala

Dirección de Investigación

Editorial UTMACH

https://investigacion.utmachala.edu.ec/portal/

Primera edición 2021

PDF interactivo 

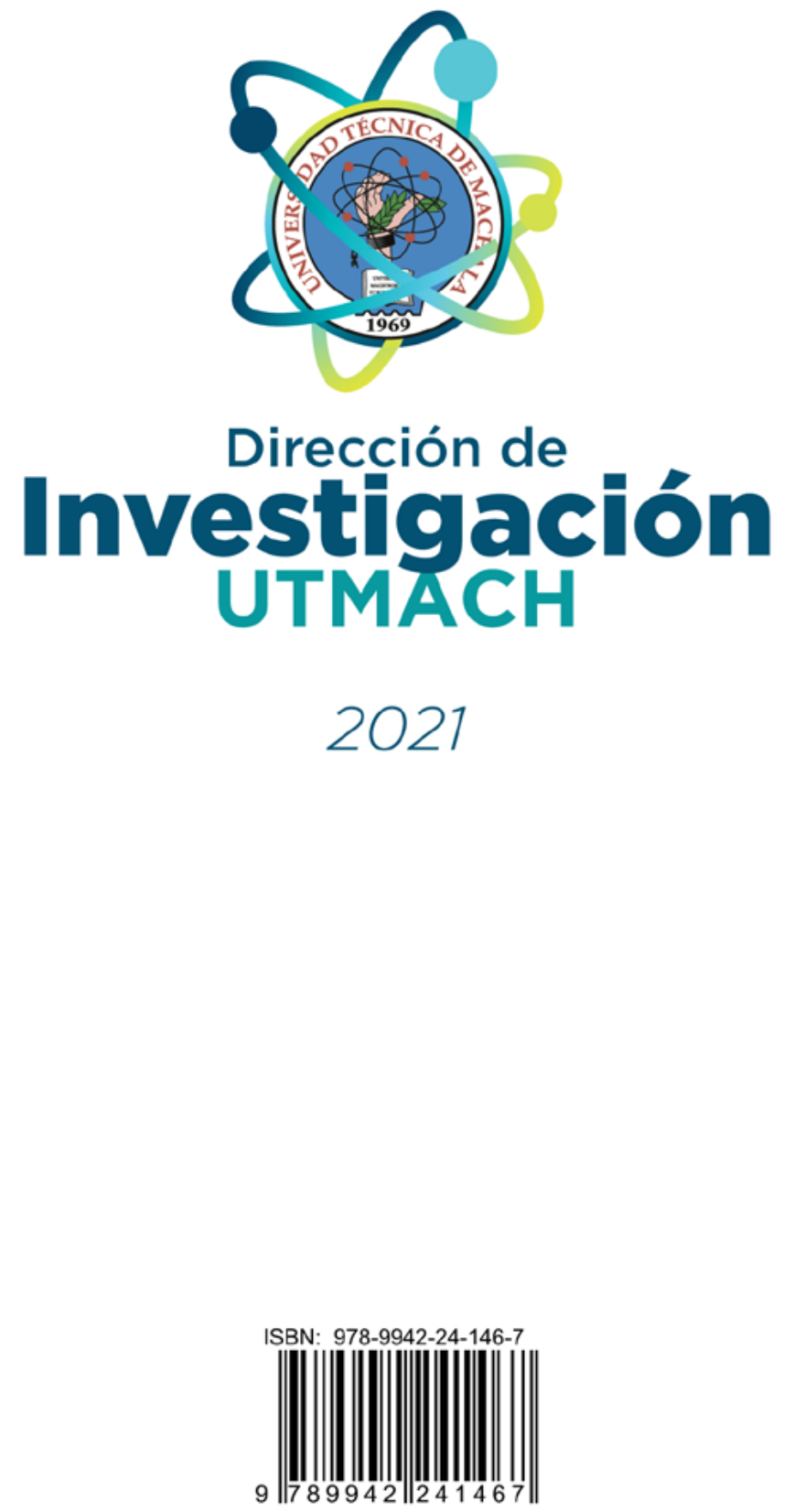